\title{
Goat Milk Free Fatty Acid Characterization During Conventional and Ohmic Heating Pasteurization
}

\author{
R. N. Pereira, ${ }^{1}$ R. C. Martins, and A. A. Vicente \\ University of Minho, IBB-Institute for Biotechnology and Bioengineering, Centre for Biological Engineering, Campus of Gualtar, 4710-057 \\ Braga, Portugal
}

\begin{abstract}
The disruption of the milk fat globule membrane can lead to an excessive accumulation of free fatty acids in milk, which is frequently associated with the appearance of rancid flavors. Solid-phase microextraction and gas chromatography techniques have been shown to be useful tools in the quantification of individual free fatty acids in dairy products providing enough sensitivity to detect levels of rancidity in milk. Therefore, the aim of this study was to characterize the short-chain and medium-chain free fatty acid profile in i) raw untreated goat milk; ii) raw goat milk passing through pumps and heating units (plate-and-frame heat exchanger and ohmic heater); and iii) processed goat milk by conventional and ohmic pasteurization to determine the influence of each treatment in the final quality of the milk. Multivariate statistical analysis has shown that the treatments studied were not responsible for the variability found on free fatty acid contents. In particular, it was possible to conclude that ohmic pasteurization at $72^{\circ} \mathrm{C}$ for $15 \mathrm{~s}$ did not promote an extended modification of free fatty acid contents in goat milk when compared with that of conventional pasteurization. Furthermore, principal component analysis showed that the capric acid can be used to discriminate goat's milk with different free fatty acid concentrations. Hierarchical cluster analysis showed evidence of the existence of correlations between contents of short and medium chain free fatty acids in goat milk.
\end{abstract}

Key words: goat milk, free fatty acid, pasteurization, ohmic heating

\section{INTRODUCTION}

An important limitation of milk treatment is the increase it provokes in FFA content. High FFA levels in milk can impair the flavor quality and shelf life of milk

Received November 18, 2007.

Accepted April 14, 2008.

${ }^{1}$ Corresponding author: rpereira@deb.uminho.pt and milk products and thus have implications for the dairy industry. Furthermore, increase of these compounds in milk is frequently associated with the development of rancid flavors (Park, 2001; Wiking, 2005). Recent research demonstrated a high correlation between short- and medium-chain FFA determined quantitatively in milk and rancidity sensory scores (González-Córdova and Vallejo-Cordoba, 2003). Free fatty acid increases can be promoted during the processing of milk upon several treatments, such as i) mechanical treatments; that is, pumping, agitation, and homogenization; ii) thermal treatments [i.e., refrigeration and heating (pasteurization, sterilization)]; and iii) enzymatic treatments [i.e., lipolysis (Raynal-Ljutovac et al., 2006)]. It has been suggested that the final level of FFA in pasteurized milk around 60 to $70 \%$ is due to lipolysis occurring during milking and milk transfer to the bulk tank (Anderson, 1983).

Furthermore, the milk temperature is also a very important factor when milk is exposed to mechanical treatments; accumulation of FFA during mechanical treatments seems to be dependent on temperature and wall shear rate (Wiking, 2005). Heating to $70^{\circ} \mathrm{C}$ or above may denature the membrane proteins of the milk fat globule (MFG), with the exposure and activation of various amino acid residues. The milk fat globule membrane (MFGM) itself can also be altered due to agitation of milk during thermal processing; in fact, agitation of warm milk in which the fat is liquid can lead to disruption or coalescence of the MFG size (Fox and McSweeney, 1998). These physical disorders in both in MFG and MFGM during pasteurization may result in an increase of FFA contents and development of rancid off-flavors when bacterial lipases, which are thermo-resistant at the temperatures of pasteurization and ultra high temperature treatments, are present in milk (Deeth, 2006).

Due to its extremely rapid heating rates, ohmic heating technology enables higher pasteurization temperatures to be applied, with consequent increase in refrigerated shelf life, without inducing coagulation or excessive denaturation of the constituent proteins (Parrott, 1992). Eventually, the presence of electric fields may 
Table 1. Identification of samples collected at the pilot plant

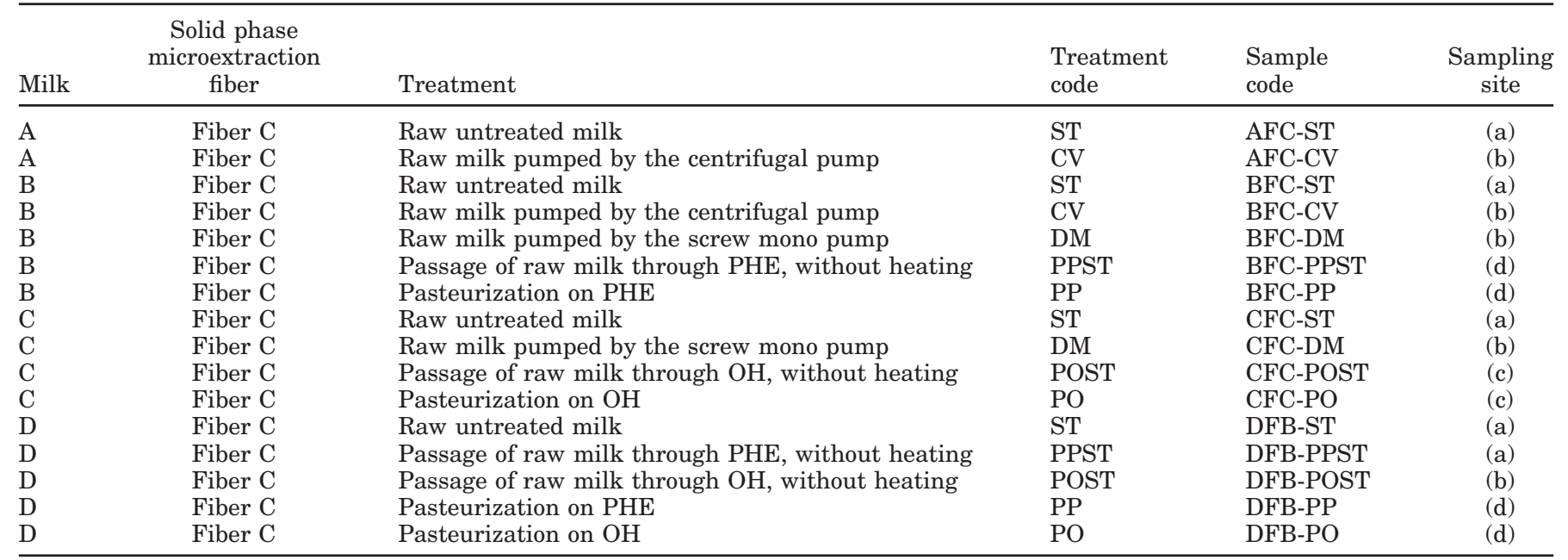

cause distortions on MFGM of MFG promoting the liberation of FFA; however, only a few scientific and technical works have been dedicated to the effects of electric fields on lipids, in particularly on FFA profile, during processing of milk and milk products (Zulueta et al., 2007).

Accurate methodologies for the quantification of short-chain FFA (C4:0-C12:0) in milk by solid phase microextraction (SPME) and GC have been already explored providing enough sensitivity to detect levels of rancidity being used to monitor the development of lipolysis in the generation of dairy flavors (GonzálezCórdova and Vallejo-Cordoba, 2001, 2003). Therefore, the main purpose of this study was to characterize FFA profile of raw and pasteurized goat milk, through the combination of SPME and GC analytical techniques and in a particular way to i) identify and characterize the major short and medium chain FFA of raw goat milk; and ii) characterize the FFA profile after ohmic and conventional pasteurization of goat milk.

\section{MATERIALS AND METHODS}

\section{Samples}

Bulk raw milk was obtained from Alpine goat breed. Goat milk samples $(60 \mathrm{~L})$ were collected in a cheese plant (Quinta dos Moinhos Novos, Lda.) located in the region of Minho (Portugal) from October to December to reduce the variability of diet and climate. The samples of milk were transported and stored at refrigeration temperatures $\left(+5^{\circ} \mathrm{C}\right)$ no more than $12 \mathrm{~h}$ before experimental treatments. In this work, a total of 4 samples of goat milk (A, B, C, and D) were analyzed.

\section{Pumping}

To evaluate if there was any influence of pumping on FFA profile before the entrance of goat milk in pasteurization units, a set of experiments were performed using a centrifugal pump (Grundfos, Denmark) and a screw mono pump (Seepex, Germany). The screw pump presented a volumetric flow rate and a rotor range of 0.05 to $0.380 \mathrm{~m}^{3} / \mathrm{h}$ and 0.01 to $0.2 \times g$ (7 to $50 \mathrm{rpm}$ ), respectively. On the other hand, the centrifugal pump worked at 2,960 rpm and maximum flow rate of approximately $10 \mathrm{~m}^{3} / \mathrm{h}$. Screw and centrifugal pumps were designed for a maximum operational pressure of 2 and 10 bar, respectively. Volumetric flow rates were monitored with a calibrated rotameter (Bailey-Fischer Porter, Germany) equipped with a control valve.

\section{Heating Units}

Two plate-and-frame heat exchangers (PHE) were used during conventional pasteurization consisting of 30 stainless steel flat plates with silicon gaskets (plate length $270 \mathrm{~mm}$, plate width $100 \mathrm{~mm}$ ). The plate pack was mounted between 2 end-plates of stainless steel AISI 316. In the first PHE, the product was heated to the full pasteurization temperature $\left(72^{\circ} \mathrm{C}\right)$, using a counter current parallel hot steam flow coming from a steam generator circuit. The steam circuit provided saturated steam at 5 bar, and this pressure was regulated at the entrance of PHE by a direct acting pressure reduction valve (Miyawaki Inc., Osaka, Japan) to control the temperature of the pasteurization process. The ohmic pasteurization was performed on a continuous laboratory scale ohmic heater $(\mathbf{O H})$ with a Teflon heating section (240-mm-length and 90-mm-width square 
section) with 2 titanium electrodes (surface coated with platinum) placed flat at the side walls of the heating section. The electrodes were connected to a single phase main electrical supply. A Teflon-coated copper-constantan thermocouple (Omega Engineering, Stamford, CT) inserted on the heating chamber provided a control signal for a proportional-integral-derivative temperature controller with fuzzy function (REX-D Series, RKC Instrument Inc., Tokyo, Japan) in the panel. A transformer unit with output voltages of 140,240 , and 400 $\mathrm{V}$ was located between the panel and the heater to give control over heat performance. The temperature controller was configured as appropriate to the process fluid, and the desired temperature of $72^{\circ} \mathrm{C}$ was then maintained by controlling the electrical supply to the heater. Electrical current varied between 5 and $30 \mathrm{~A}$ and the electric field applied between electrodes was $14.4 \mathrm{~V} / \mathrm{cm}$. During both conventional and ohmic pasteurization, milk was kept at $72^{\circ} \mathrm{C}$ for $15 \mathrm{~s}$ (holding time), whereas it crossed through a thermically insulated holding tube. For further control during pasteurization, temperature was continuously monitored in the holding tube by the introduction of a thermocouple connected to a data logger (Thermocouple Input USB-9211, National Instruments, Austin, TX). If the temperature was at or above the required temperature, then the product was considered to be pasteurized; otherwise, a divert valve returned it to a discard tank. Pasteurized milk passed through the second PHE where it was cooled by the use of an externally counter current parallel cooling water flow.

\section{SPME Fiber}

For the extraction of FFA from goat milk samples, SPME was performed with 3 different fibers of the same kind [fiber A (FA), fiber B (FB), and fiber C (FC)] coated with $85 \mu \mathrm{m}$ polyacrylate for analytes group polar semi volatiles (catalog no. 57304, Supelco Co., Bellefonte, PA). During extractions, each fiber was mounted in a SPME holder device for use with manual sampling (catalog no. 57330-U, Supelco Co.).

\section{Experimental Design}

During the experiments, the raw goat milk was stored in a buffer tank from where it was pumped by the screw mono pump or by the centrifugal pump. Conventional and ohmic pasteurization were performed in a PHE or in an $\mathrm{OH}$ unit, respectively. All the samples of milk received a specific code, according with the fiber used in SPME extraction procedures and treatment applied [e.g., DFB-PO identifies a subsample from milk D, where FFA were extracted by FB (fiber FB) and the treatment applied was ohmic pasteurization (PO; see Table 1)].

Figure 1 illustrates a scheme of the pilot plant used in the experiments. Differently treated goat milk samples were collected from 3 different sampling sites (a, b, c, and d) of the pilot plant. Three sets of treatments were conducted in raw goat milk. The first set was intended to determine the pumping effects on FFA profile of raw goat milk samples. Before milk was being pumped, samples of untreated raw goat milk (ST) were collected from a valve placed at the middle of the buffer tank [sampling site (a)]. Pumping of raw goat milk samples was made through a screw or a centrifugal pump, which was achieved through the action of a bypass valve. Raw goat milk samples treated by screw (DM) and centrifugal (CV) pumps were collected separately at sampling site (b). For each pump treatment, approximately $25 \mathrm{~L}$ of raw milk was pumped through the system at $15^{\circ} \mathrm{C}$. The centrifugal and screw pump worked at 392 and $0.02 \times g(2,960 \mathrm{rpm}$ and $20 \mathrm{rpm})$, respectively, and the flow rate passing through both pumps was regulated to $156 \mathrm{~L} / \mathrm{h}$ (maximum flow rate achieved for the centrifugal pump at the established conditions).

The second set of treatments was conducted to determine the influence of the passage of milk through different pasteurization units, without applying heat, on FFA profile. Immediately before milk being pumped through pasteurization units, samples of untreated raw goat milk (ST) were again collected at sampling site (a). Then, goat milk samples were pumped (at $15^{\circ} \mathrm{C}$ ) by the screw pump through the plate heat exchanger and ohmic pasteurization lines. Raw goat milk samples subjected to the passage through PHE (PPST) were collected in sampling site (c) and subjected to the passage through OH (POST) were collected separately in sampling sites (c) and (d). For these treatments, the flow rate and rotation of screw pump were regulated at 70.8 $\mathrm{L} / \mathrm{h}$ and $0.01 \times g(11 \mathrm{rpm})$, respectively.

The third set of treatments was conducted to determine the influence of the passage of milk through the $\mathrm{PHE}$ and $\mathrm{OH}$ combined with the pasteurization process on FFA profile. Goat milk samples pasteurized in PHE (PP) were collected in sampling point (c) and pasteurized in $\mathrm{OH}(\mathrm{PO})$ were collected separately in sampling points (c) and (d) of the pilot plant. For these treatments, the flow rate and rotation of screw pump were regulated at $70.8 \mathrm{~L} / \mathrm{h}$ and $11 \mathrm{rpm}$, respectively. At these conditions the holding time and effectiveness of pasteurization processes was achieved. For each different group of samples at least 5 replicates of $50 \mathrm{~mL}$ were collected from the respective sampling sites of the pilot plant and stored at $-18^{\circ} \mathrm{C}$ for further extraction, identification, and quantification of FFA. 


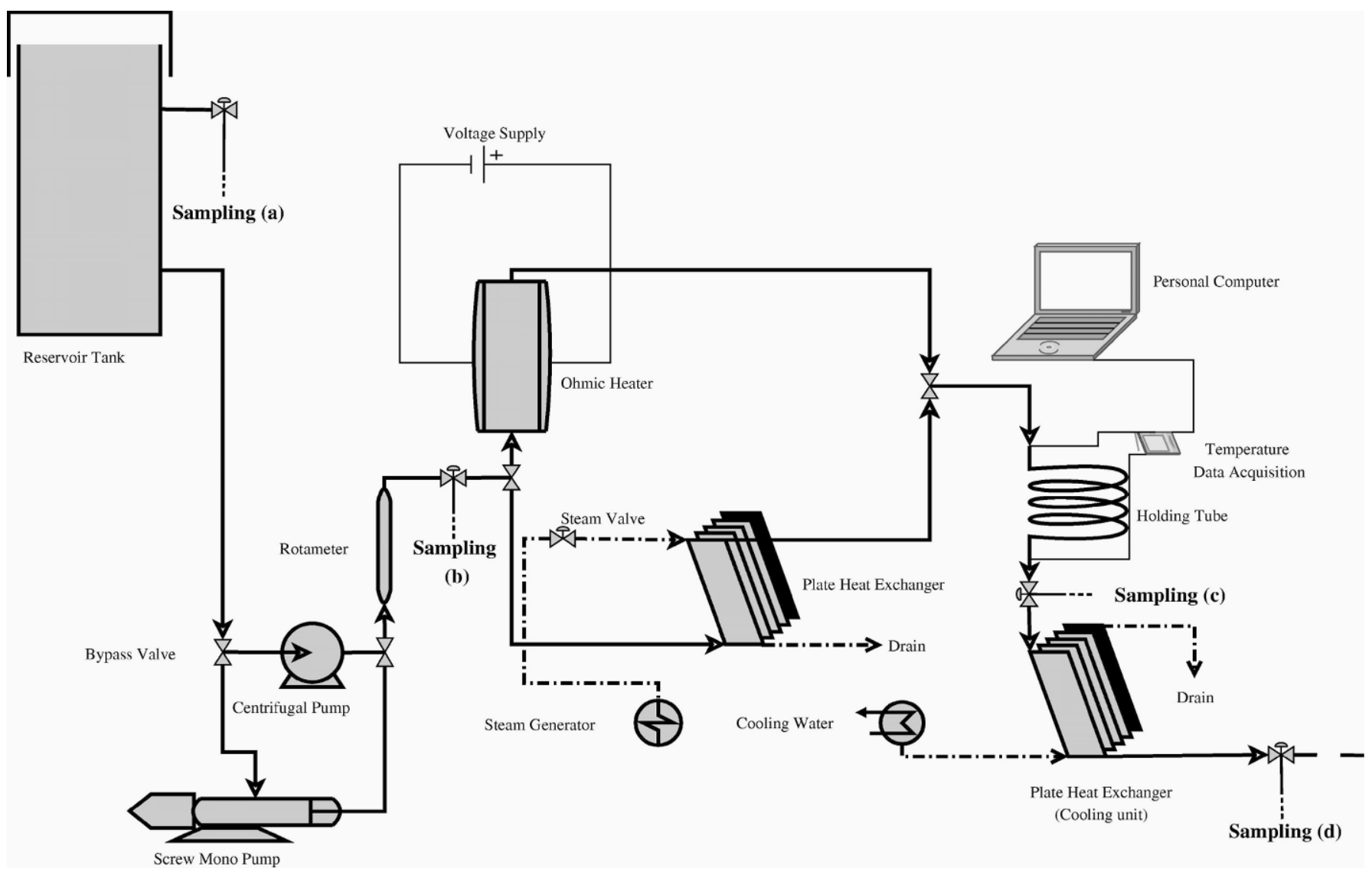

Figure 1. Pilot-plant scheme used in conventional and ohmic pasteurization of goat milk.

\section{FFA Analysis}

Extraction and quantification of FFA in goat milk samples of each treatment group performed through the combination of SPME and GC, follows methodologies described in previous works (González-Córdova and Vallejo-Cordoba, 2001, 2003). Analysis and identification of FFA through GC was performed using a Chrompack 9001 gas chromatograph (Varian, Palo Alto, CA) equipped with a flame ionization detector (FID). The target compounds were separated using a capillary CPFFAP CB column $(25 \mathrm{~mm} \times 0.32 \mathrm{~mm}$ i.d., with an outside diameter of $0.45 \mathrm{~mm}$ and film thickness of $0.30 \mu \mathrm{m}$; Varian). The analytes (extracted previously by SPME) were continuously desorbed at $250^{\circ} \mathrm{C}$ for $5 \mathrm{~min}$ in the injection port of the GC by exposing the SPME fiber immediately after the needle was introduced into the insert to avoid the peak splitting effect. After injection, the following column temperature sequence was used: an initial temperature of $35^{\circ} \mathrm{C}$ was maintained for 2 min, increased to $230^{\circ} \mathrm{C}$ at a rate of $5^{\circ} \mathrm{C} / \mathrm{min}$, and held at $230^{\circ} \mathrm{C}$ for $20 \mathrm{~min}$. The FID was maintained at $280^{\circ} \mathrm{C}$, and helium (UHP, ultra-high purity) at $2.0 \mathrm{~mL} / \mathrm{min}$ was used as the carrier gas. Air and hydrogen (UHP) made up the FID flame, and the makeup gas was nitrogen (UHP).

\section{Quantitative Analysis}

Calibration curves using the internal standard technique (valeric (C5:0) acid was used as internal standard) were performed for butyric (C4:0), caproic (C6:0), caprylic (C8:0), capric (C10:0), lauric (C12:0), and myristic acids (C14:0; $>99.5 \%$ purity; Supelco Co.). Standard stock solutions of C4:0 (20,000 mg/L), C5:0 $(20,000 \mathrm{mg} /$ $\mathrm{L}), \mathrm{C} 6: 0$ (20,000 mg/L), C8:0 (5,000 mg/L), C10:0 (5,000 $\mathrm{mg} / \mathrm{L}), \mathrm{C} 12: 0(5,000 \mathrm{mg} / \mathrm{L})$, and C14:0 $(20,000 \mathrm{mg} / \mathrm{L})$ were prepared in methanol (Chromosolv, Riedel-deHaën, Germany). These were added afterward to the goat milk samples to get final concentrations ranging from 2 to $60 \mathrm{mg} / \mathrm{L}$. The internal standard (C5:0) was added to a final concentration of $40 \mathrm{mg} / \mathrm{L}$ in all milk samples. For the elaboration of calibration curves, extractions of FFA (C4:0 to C14:0) from goat milk were performed by using FA, FB, and FC. For each fiber and 
(a)

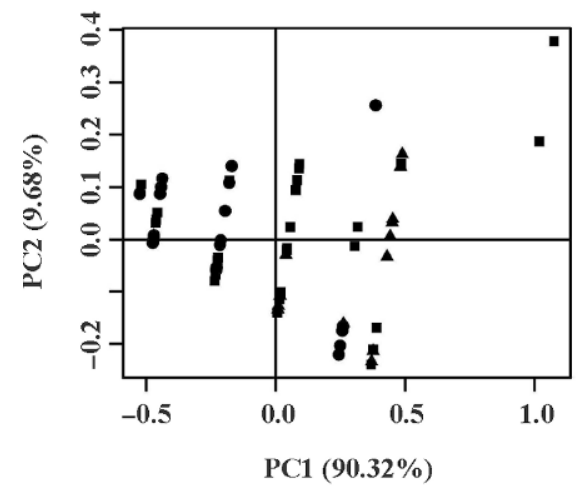

(d)

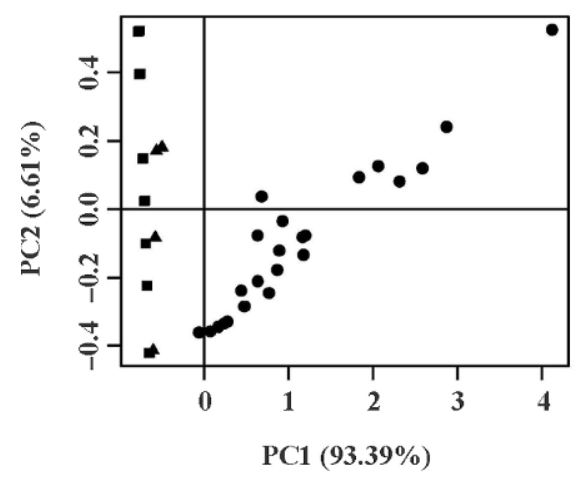

(b)

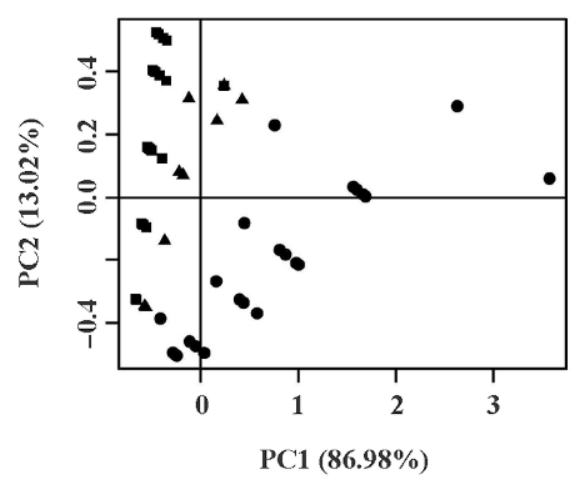

(e)

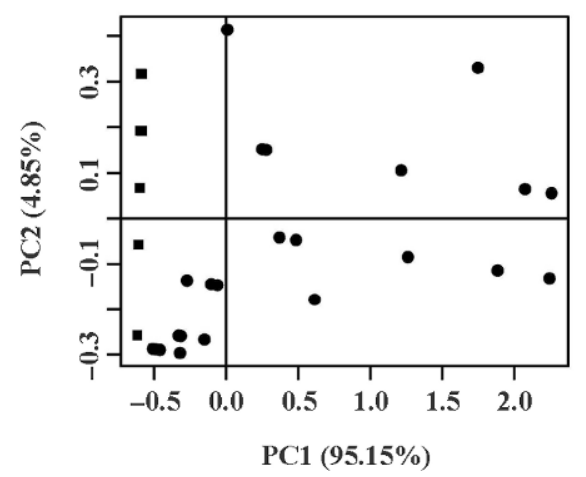

(c)

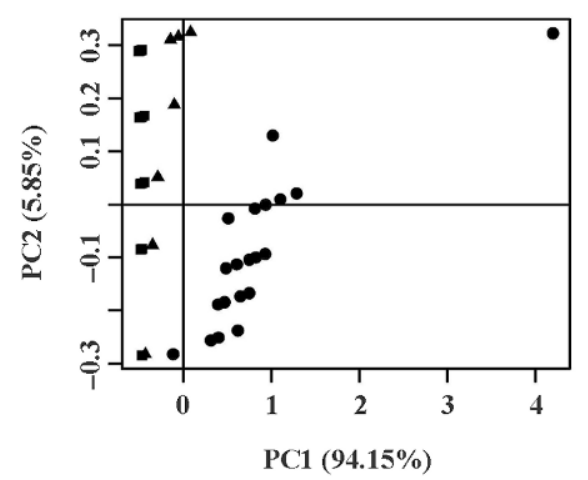

(f)

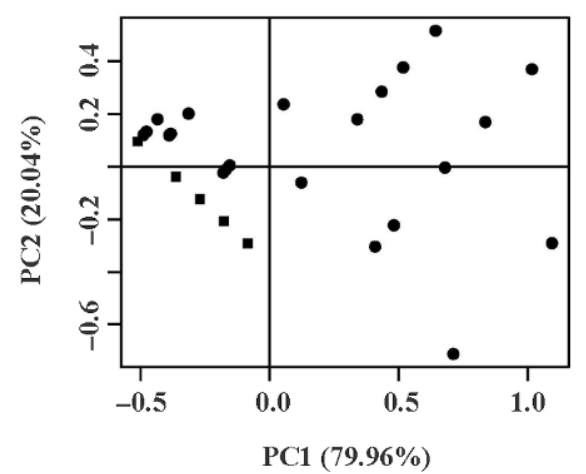

Figure 2. Principal component analysis (PCA) from calibration data of $\mathrm{C}_{4: 0}(\mathrm{a}), \mathrm{C}_{6: 0}(\mathrm{~b}), \mathrm{C}_{8: 0}(\mathrm{c}), \mathrm{C}_{10: 0}$ (d), $\mathrm{C}_{12: 0}(\mathrm{e})$, and $\mathrm{C}_{14: 0}$ (f), using

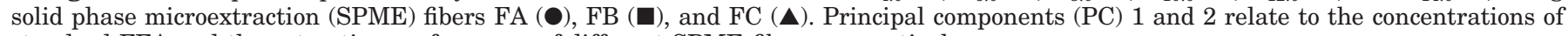
standard FFA and the extraction performance of different SPME fibers, respectively.

concentration of FFA standards added to milk at least 3 consecutive SPME extractions were made.

\section{Statistical Analysis}

All statistical analyses involving the experimental data were performed using $\mathrm{R}$ 1.9.0 for Linux. Calibration curves for each FFA were constructed by applying simple and robust linear regression on concentrations $(\mathrm{mg} / \mathrm{L})$ versus the quotient of the respective FFA GC peak area over the internal standard (C5:0) area. Linear correlations among FFA standards spiked in raw goat milk and concentrations extracted by SPME fibers were assessed through the calculation of $\mathrm{R}^{2}, \mathrm{SE}$, and probability values for each calibration curve (lack-of-fit test for simple linear regression). One-way ANOVA and Tukey multiple comparison tests were performed to evaluate if there was significant differences on FFA composition in each goat milk sample (A, B, C, and D). Analysis of variance linear model was tested for linearity and residual's normality. Principal component analysis (PCA) was applied to all calibration data and was performed to identify patterns and to highlight similarities and differences in FFA percentage weights in goat milk samples subjected to the treatments studied.

Data from PCA was pretreated by mean centering and scaling processing tools. The PCA scores and loadings were further analyzed by hierarchical cluster analysis to find correspondences between samples and FFA compositions (Krzanowski, 1998) and consequently to determine the influence of different mechanical and thermal treatments in goat milk short and medium chain FFA profile.

\section{RESULTS AND DISCUSSION}

\section{Development of the Calibration Method}

Previous studies show that extraction of FFA by SPME is sensitive to factors such as sample preparation, volume, temperature, exposure time, and fiber coatings (González-Córdova and Vallejo-Cordoba, 2001, 2003). Such constraints led us to perform a deeper eval- 
Table 2. Simple and robust calibration curves for FFA standards spiked in raw goat milk and extracted by solid phase microextraction (SPME) $85-\mu$ m polyacrylate fiber B (FB)

\begin{tabular}{llccccc}
\hline & & & & & \multicolumn{3}{c}{$\begin{array}{c}\text { Correlation } \\
\text { coefficient } \\
\text { Calibration }\end{array}$} \\
& \multicolumn{1}{c}{ FFA } & \multicolumn{1}{c}{$\mathrm{C}_{0} / \mathrm{C}_{\mathrm{IS}}{ }^{1}$} & Slope $^{2}$ & $\mathrm{SE}$ & $P$-value \\
\hline Simple & Butyric $\left(\mathrm{C}_{4: 0}\right)$ & $0.502 \pm 0.067$ & $0.0737 \pm 0.034$ & 0.300 & 0.113 & $3.96 \times 10^{-2}$ \\
& Caproic $\left(\mathrm{C}_{6: 0}\right)$ & $0.230 \pm 0.068$ & $0.657 \pm 0.098$ & 0.208 & 0.578 & $1.72 \times 10^{-7}$ \\
& Caprylic $\left(\mathrm{C}_{8: 0}\right)$ & $0.228 \pm 0.047$ & $0.722 \pm 0.192$ & 0.165 & 0.298 & $7.31 \times 10^{-4}$ \\
& Capric $\left(\mathrm{C}_{10: 0}\right)$ & $0.410 \pm 0.053$ & $0.931 \pm 0.239$ & 0.176 & 0.403 & $8.93 \times 10^{-4}$ \\
Robust & Butyric $\left(\mathrm{C}_{4: 0}\right)$ & $0.300 \pm 0.077$ & $0.338 \pm 0.073$ & 0.234 & 0.775 & $8.44 \times 10^{-5}$ \\
& Caproic $\left(\mathrm{C}_{6: 0}\right)$ & $0.218 \pm 0.075$ & $0.660 \pm 0.107$ & 0.209 & 0.952 & $1.70 \times 10^{-7}$ \\
& Caprylic $\left(\mathrm{C}_{8: 0}\right)$ & $0.207 \pm 0.047$ & $0.765 \pm 0.142$ & 0.181 & 0.702 & $2.32 \times 10^{-4}$ \\
& Capric $\left(\mathrm{C}_{10: 0}\right)$ & $0.326 \pm 0.052$ & $1.436 \pm 0.345$ & 0.155 & 0.729 & $3.99 \times 10^{-4}$ \\
\hline
\end{tabular}

\footnotetext{
${ }^{1}$ Initial concentration of FFA $\left(\mathrm{C}_{0}\right)$ and internal standard concentration $\left(\mathrm{C}_{\mathrm{IS}}\right)$.
}

${ }^{2} \mathrm{GC}$ peak area and GC internal standard peak.

uation of the extraction methodology by application of PCA to the calibration curves. Furthermore, the use of PCA to calibrate results allowed the monitoring of the performance and reproducibility of the extraction procedures. In this work, polyacrylate SPME fibers (FA, FB, and FC) were tested for the extraction of C4:0 to C14:0 acids. Figure 2 shows the plot of the scores for the 2 first principal components (PC1 and PC2) of calibration data for C4:0 to C14:0 acids (Figure 2a to 2f). For each plot, $\mathrm{PC} 1$ relates the different concentrations of standard FFA added to goat milk, whereas PC2 describes the differences on extraction performances between the SPME fibers (FA, FB, and FC) used for the extraction of FFA during calibration procedures. From the PCA of the calibration curves of $\mathrm{C} 4: 0$ to $\mathrm{C} 12: 0$, it is possible to observe that PC1 accounted for more than $85 \%$ of the total variability, thus indicating that SPME technique is adequate for the differentiation of the standard FFA concentrations (ranging from 2 to $60 \mathrm{mg} / \mathrm{L}$ ) added to the goat milk samples. However, the differentiation between the different standard concentrations of C14:0 acid spiked in milk revealed to be more difficult to achieve, once for this case PC1 was below $80 \%$. Further- more, PC2 was responsible for more than 5\% of total variability (with exception of $\mathrm{C} 12: 0$ ), thus showing that fibers FA, FB, and FC with the same fiber coating have presented significantly different extraction performances. Consequently, fixing the best SPME operating conditions and using the same type of fiber coating, will not necessarily mean that the extraction is always equal. Therefore, the key issue of SPME is to obtain for each fiber a reproducible and valid calibration curve that can be used for FFA GC quantification.

Simple and robust calibration curves for C4:0, C6:0, $\mathrm{C} 8: 0$, and capric C10:0 free acids followed linear relationships with highly significant $(P<0.01)$ correlation coefficients (see Tables 2 and 3). However, one can observe that robust least squares (LS) calibration has presented significantly better correlation coefficients for C4:0 to C10:0 acids. Such observation occurs because the extraction procedure used in the SPME methodology is prone to experimental errors, developing outliers in some of the extraction replicates. Even one outlying observation can destroy simple LS estimation, resulting in parameter estimates that do not provide useful information for the majority of the data. This was observed

Table 3. Simple and robust calibration curves for FFA standards spiked in raw goat milk and extracted by solid phase microextraction (SPME) $85-\mu \mathrm{m}$ polyacrylate fiber C (FC)

\begin{tabular}{|c|c|c|c|c|c|c|}
\hline Calibration & FFA & $\mathrm{C}_{0} / \mathrm{C}_{\mathrm{IS}}{ }^{1}$ & Slope $^{2}$ & SE & $\begin{array}{c}\text { Correlation } \\
\text { coefficient } \\
\left(\mathrm{r}^{2}\right)\end{array}$ & $P$-value \\
\hline \multirow[t]{4}{*}{ Simple } & Butyric $\left(\mathrm{C}_{4: 0}\right)$ & $0.250 \pm 0.074$ & $1.88 \pm 0.226$ & 0.186 & 0.842 & $1.46 \times 10^{-6}$ \\
\hline & Caproic $\left(\mathrm{C}_{6: 0}\right)$ & $0.137 \pm 0.101$ & $1.114 \pm 0.197$ & 0.158 & 0.794 & $7.81 \times 10^{-4}$ \\
\hline & Caprylic $\left(\mathrm{C}_{8: 0}\right)$ & $0.115 \pm 0.064$ & $1.039 \pm 0.184$ & 0.089 & 0.815 & $1,34 \times 10^{-4}$ \\
\hline & Capric $\left(\mathrm{C}_{10: 0}\right)$ & $-0.0150 \pm 0.099$ & $2.935 \pm 0.581$ & 0.094 & 0.831 & $7.24 \times 10^{-3}$ \\
\hline \multirow[t]{4}{*}{ Robust } & Butyric $\left(\mathrm{C}_{4: 0}\right)$ & $0.142 \pm 0.074$ & $2.56 \pm 0.299$ & 0.115 & 0.985 & $3.60 \times 10^{-7}$ \\
\hline & Caproic $\left(\mathrm{C}_{6: 0}\right)$ & $0.121 \pm 0.104$ & $1.127 \pm 0.203$ & 0.151 & 0.983 & $7.60 \times 10^{-4}$ \\
\hline & Caprylic $\left(\mathbf{C}_{8: 0}\right)$ & $0.116 \pm 0.067$ & $1.036 \pm 0.194$ & 0.114 & 0.921 & $1.34 \times 10^{-4}$ \\
\hline & Capric $\left(\mathrm{C}_{10: 0}\right)$ & $-0.0134 \pm 0.104$ & $2.918 \pm 0.608$ & 0.113 & 0.864 & $7.24 \times 10^{-3}$ \\
\hline
\end{tabular}

${ }^{1}$ Initial concentration of FFA $\left(\mathrm{C}_{0}\right)$ and internal standard concentration $\left(\mathrm{C}_{\mathrm{IS}}\right)$.

${ }^{2} \mathrm{GC}$ peak area/GC internal standard peak. 
(a)

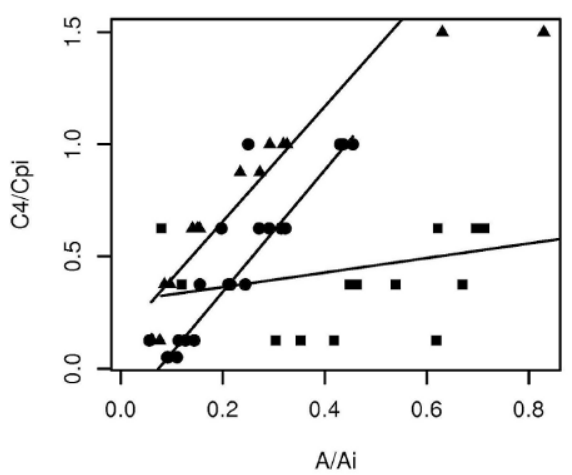

(d)

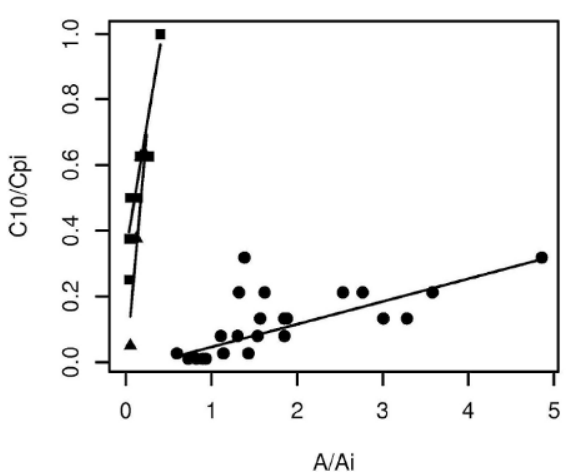

(b)

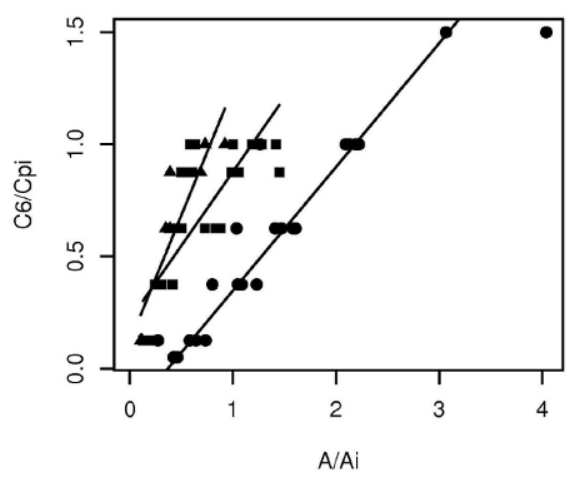

(e)

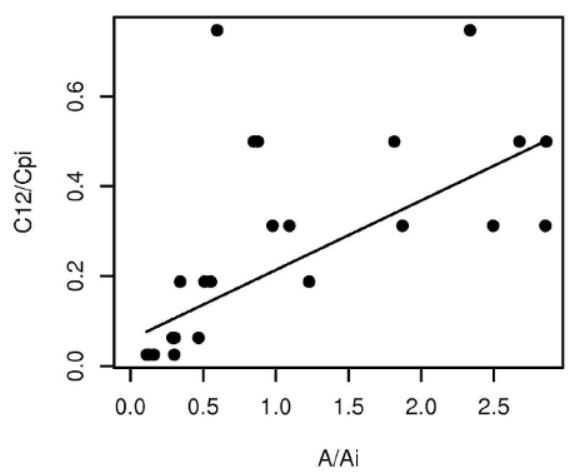

(c)

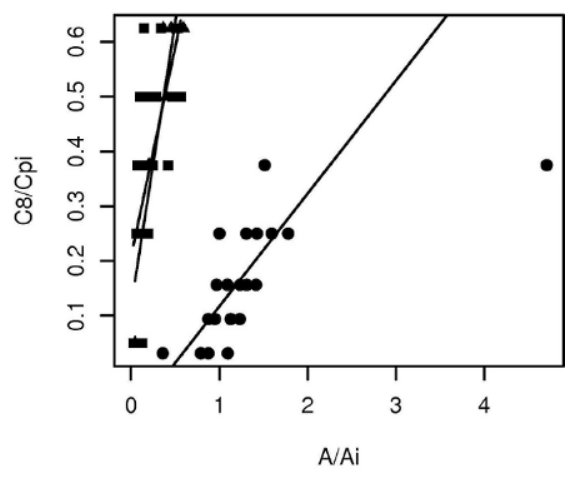

(f)

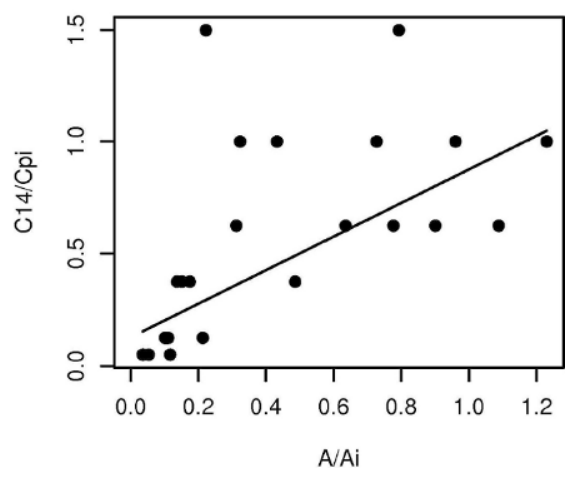

Figure 3. Robust linear regression for C4:0 (a), C6:0 (b), C8:0 (c), C10:0 (d), C12:0 (e), and C14:0 (f), extracted by using solid phase microextraction fibers FA $(\bullet), \mathrm{FB}(\boldsymbol{\square})$, and FC $(\mathbf{\Delta})$. C4 to $\mathrm{C} 10=$ concentration of FFA; Cpi = concentration of internal standard; A = chromatogram peak area of FFA; and $\mathrm{Ai}=$ chromatogram peak area of internal standard.

for all the FFA studied, and for that reason, robust LS calibration was applied to all calibration curves using the Huber function, which has a breakdown point (50\%) to the existing outliers in SPME extractions. The breakdown point of $50 \%$ allowed fitting a model that represents the information in the majority of the calibration data. Therefore, our results provide evidence that robust LS calibrations should always be used when performing FFA quantification in goat milk using SPME. Attempts to build a calibration curve for C12:0 and C14:0 acids failed. Results from PCA analysis and robust regression provided evidence that the concentrations of C12:0 and C14:0 extracted by FA, FB, and FC during calibration procedures were highly random and irreproducible (see Figure 3). Poor accuracy on the extraction of these fatty acids could be related with their higher molecular weight, poor volatilization, and solubility problems in goat milk samples. The difficulties encountered in the calibration of medium chain FFA, such as C12:0, were also experienced in other SPME studies (González-Córdova and Vallejo-Cordoba, 2001).

\section{FFA Characterization}

Butyric (C4:0), caproic (C6:0), caprylic (C8:0), and capric (C10:0) acids were identified and quantified. Peaks for short- and medium-chain FFA were completely resolved in the chromatographic conditions stated; lauric (C12:0) and myristic (C14:0) acids were also identified but not quantified.

For each milk, the concentrations of the FFA were calculated for untreated (ST) and treated samples (DM, CV, PPST, POST, PP, and PO) independently extracted and analyzed. Table 4 shows the mean concentrations of individual and total FFA as well as their respective standard deviation in the different treated goat milk samples. The most abundant FFA in the different samples of raw untreated goat milk (ST) was C10:0, the mean concentration of which varied between 18.53 and $61.10 \mathrm{mg} / \mathrm{L}$. Goat milk A presented a higher concentration of total FFA in AFC-ST samples (104.96 \pm 17.76 $\mathrm{mg} / \mathrm{L})$ than goat milk B in BFC-ST $(49.88 \pm 4.28 \mathrm{mg} /$ $\mathrm{L})$, milk C in CFC-ST $(46.73 \pm 9.94 \mathrm{mg} / \mathrm{L})$, and milk D in DFB-ST (54.78 $\pm 2.35 \mathrm{mg} / \mathrm{L})$ samples. Univariate 
Table 4. Mean concentrations of FFA in different goat milk samples

\begin{tabular}{|c|c|c|c|c|c|c|}
\hline \multirow[b]{2}{*}{ Milk } & \multicolumn{6}{|c|}{ Composition $(\mathrm{mg} / \mathrm{L})$} \\
\hline & Sample & $\begin{array}{c}\text { Butyric } \\
\left(\mathrm{C}_{4: 0}\right) \mu^{1} \pm \mathrm{SD}^{2}\end{array}$ & $\begin{array}{c}\text { Caproic } \\
\left(\mathrm{C}_{6: 0}\right) \mu \pm \mathrm{SD}\end{array}$ & $\begin{array}{c}\text { Caprylic } \\
\left(\mathrm{C}_{8: 0}\right) \mu \pm \mathrm{SD}\end{array}$ & $\begin{array}{c}\text { Capric } \\
\left(\mathrm{C}_{10: 0}\right) \mu \pm \mathrm{SD}\end{array}$ & $\begin{array}{c}\text { Total } \\
\mu \pm \text { SD }\end{array}$ \\
\hline $\mathrm{A}$ & AFC-ST & $9.99 \pm 1.22^{\mathrm{a}}$ & $13.47 \pm 1.79^{\mathrm{a}}$ & $20.40 \pm 3.18^{\mathrm{a}}$ & $61.10 \pm 11.79^{a}$ & $104.96 \pm 17.76^{\mathrm{a}}$ \\
\hline A & AFC-CV & $10.08 \pm 1.23^{\mathrm{a}}$ & $13.46 \pm 1.47^{\mathrm{a}}$ & $20.20 \pm 2.60^{\mathrm{a}}$ & $64.37 \pm 12.31^{\mathrm{a}}$ & $108.13 \pm 17.14^{\mathrm{a}}$ \\
\hline $\mathrm{B}$ & BFC-ST & $9.12 \pm 0.56^{\mathrm{b}}$ & $8.66 \pm 0.41^{b}$ & $10.09 \pm 0.59^{b}$ & $22.02 \pm 3.42^{\mathrm{b}}$ & $49.88 \pm 4.28^{\mathrm{b}}$ \\
\hline B & $\mathrm{BFC}-\mathrm{CV}$ & $9.17 \pm 0.68^{b}$ & $8.89 \pm 0.58^{\mathrm{b}}$ & $10.57 \pm 0.99^{b}$ & $24.78 \pm 3.58^{\mathrm{b}}$ & $53.41 \pm 5.09^{b}$ \\
\hline B & BFC-DM & $9.06 \pm 0.64^{\mathrm{b}}$ & $8.61 \pm 0.68^{b}$ & $10.07 \pm 0.99^{b}$ & $22.27 \pm 5.18^{b}$ & $50.01 \pm 7.10^{\mathrm{b}}$ \\
\hline B & BFC-PPST & $9.68 \pm 0.67^{b}$ & $9.92 \pm 0.59^{c}$ & $12.26 \pm 0.73^{\mathrm{c}}$ & $31.43 \pm 4.15^{\mathrm{c}}$ & $63.29 \pm 5.61^{\mathrm{c}}$ \\
\hline B & BFC-PP & $8.91 \pm 0.44^{\mathrm{b}}$ & $8.42 \pm 0.19^{b}$ & $10.00 \pm 0.42^{\mathrm{b}}$ & $20.98 \pm 2.40^{\mathrm{b}}$ & $48.31 \pm 2.77^{\mathrm{b}}$ \\
\hline $\mathrm{C}$ & CFC-ST & $10.48 \pm 1.67^{\mathrm{d}}$ & $8.49 \pm 1.17^{\mathrm{d}}$ & $9.23 \pm 1.39^{\mathrm{d}}$ & $18.53 \pm 5.80^{\mathrm{d}}$ & $46.73 \pm 9.94^{\mathrm{d}}$ \\
\hline $\mathrm{C}$ & CFC-POST & $9.93 \pm 0.59^{\mathrm{d}}$ & $8.38 \pm 0.42^{\mathrm{d}}$ & $9.29 \pm 0.48^{\mathrm{d}}$ & $17.66 \pm 1.65^{\mathrm{d}}$ & $45.26 \pm 2.73^{\mathrm{d}}$ \\
\hline $\mathrm{C}$ & CFC-PO & $9.10 \pm 0.31^{\mathrm{e}}$ & $7.88 \pm 0.34^{\mathrm{d}}$ & $8.64 \pm 0.50^{\mathrm{d}}$ & $16.56 \pm 2.75^{\mathrm{d}}$ & $42.18 \pm 3.77^{\mathrm{d}}$ \\
\hline $\mathrm{D}$ & DFB-ST & $13.39 \pm 0.24^{f}$ & $10.77 \pm 0.58^{\text {fh }}$ & $10.84 \pm 0.44^{\text {fh }}$ & $19.77 \pm 1.57^{\mathrm{fg}}$ & $54.78 \pm 2.35^{f}$ \\
\hline $\mathrm{D}$ & DFB-PPST & $13.25 \pm 0.34^{\mathrm{f}}$ & $11.14 \pm 0.30^{\mathrm{f}}$ & $11.79 \pm 0.43^{\mathrm{g}}$ & $22.30 \pm 2.14^{\mathrm{f}}$ & $58.48 \pm 2.52^{\mathrm{g}}$ \\
\hline $\mathrm{D}$ & DFB-POST & $13.53 \pm 0.26^{\mathrm{f}}$ & $10.45 \pm 0.34^{\mathrm{gh}}$ & $10.46 \pm 0.53^{\mathrm{h}}$ & $18.65 \pm 2.30^{\mathrm{g}}$ & $53.09 \pm 3.11^{\mathrm{f}}$ \\
\hline $\mathrm{D}$ & DFB-PP & $12.72 \pm 0.23^{\mathrm{g}}$ & $10.40 \pm 0.13^{\mathrm{gh}}$ & $11.14 \pm 0.29^{\mathrm{f}}$ & $21.49 \pm 1.02^{\mathrm{f}}$ & $55.74 \pm 1.23^{\mathrm{f}}$ \\
\hline $\mathrm{D}$ & DFB-PO & $12.83 \pm 0.57^{\mathrm{g}}$ & $10.79 \pm 1.61^{\mathrm{g}}$ & $11.63 \pm 2.32^{\mathrm{f}, \mathrm{h}}$ & $21.37 \pm 3.46^{\mathrm{fg}}$ & $54.29 \pm 1.50^{\mathrm{f}}$ \\
\hline
\end{tabular}

${ }^{\mathrm{a}-\mathrm{h}}$ For each milk (A, B, C, and D), means in columns followed by the same letter are not significantly different $(P>0.05)$ according to ANOVA.

${ }^{1}$ Mean concentrations from at least one group consisting of 5 samples.

${ }^{2}$ Standard deviation of the mean.

statistical analysis by one-way ANOVA was then performed when trying to evaluate if the differences on mean FFA percentage weight of untreated samples belonging to the different milks (AFC-ST, BFC-ST, CFCST, and DFB-ST) were significant at the beginning of the experiments. Thus, despite the fact that all samples of raw goat milk had been collected from the same herds, it was possible to conclude that the FFA profile changed significantly $(P<0.01)$ during this work. The C10:0 acid, which accounted for more than $30 \%$ of total FFA quantified in untreated raw goat milk samples, showed significantly higher $(P<0.01)$ values in samples AFC-ST and BFC-ST (from milk collected during October/November) than in samples CFC-ST and DFB-ST (from milk collected during November/December). Short-chain FFA (C4:0 and C6:0) were not so representative in the total FFA concentration, and their concentrations remained constant in the different milks analyzed and were extremely affected by the variations of C10:0. Consequently, the mean percentage weights of $\mathrm{C} 4: 0$ and $\mathrm{C} 6: 0$ were significantly lower in samples AFCST and BFC-ST than in CFC-ST and DFB-ST (see Figure 4). The percentage weight of $\mathrm{C}_{8: 0}$ remained constant; no significant differences $(P>0.05)$ were noticed in all samples of untreated raw goat milk analyzed.

After subjecting the milks to the different treatments (DM, CV, PPST, POST, PP, and PO), univariate statistical analysis was again performed separately on the results from each milk sample (A, B, C, and D) when trying to distinguish the differences on FFA profile (Table 5). In general, this analysis was made with particular attention to the variations on the percentage weight of C10:0 acid. As mentioned before, this FFA was the most representative in the untreated goat milk samples, being therefore easier to notice significant variations on its weight percentage during treatments. For goat milk A, no significant differences $(P>0.05)$ have been noticed in FFA percentage among the respective groups of treated samples. Through the performance of ANOVA it was possible to observe that the centrifugal

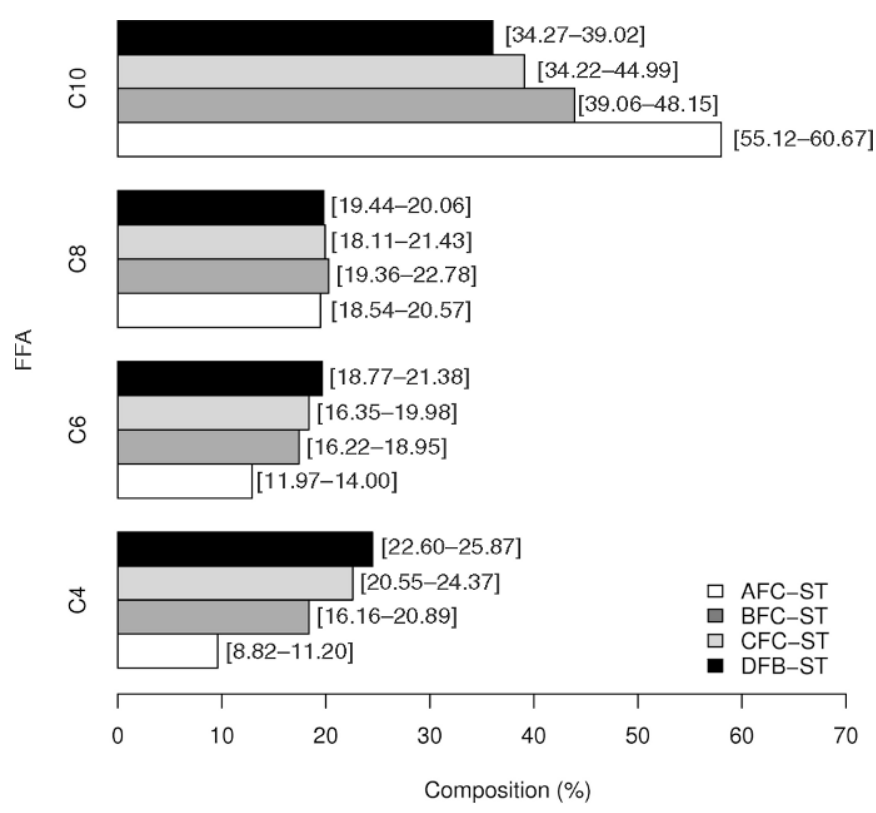

Figure 4. Maximum and minimum percentage weight of FFA in untreated raw milk samples. 
Table 5. Mean relative percentage weight of FFA in different goat milk samples

\begin{tabular}{llcccc}
\hline \multicolumn{5}{c}{ Composition $(\%)$} \\
\cline { 2 - 6 } Milk & Sample & $\begin{array}{c}\text { Butyric } \\
\left(\mathrm{C}_{4: 0}\right) \mu^{1} \pm \mathrm{SD}^{2}\end{array}$ & $\begin{array}{c}\text { Caproic } \\
\left(\mathrm{C}_{6: 0}\right) \mu \pm \mathrm{SD}\end{array}$ & $\begin{array}{c}\text { Caprylic } \\
\left(\mathrm{C}_{8: 0}\right) \mu \pm \mathrm{SD}\end{array}$ & $\begin{array}{c}\text { Capric } \\
\left(\mathrm{C}_{10: 0}\right) \mu \pm \mathrm{SD}\end{array}$ \\
\hline A & AFC-ST & $9.61 \pm 0.75^{\mathrm{a}}$ & $12.91 \pm 0.58^{\mathrm{a}}$ & $19.48 \pm 0.65^{\mathrm{a}}$ & $58.01 \pm 1.59^{\mathrm{a}}$ \\
A & AFC-CV & $9.41 \pm 0.81^{\mathrm{a}}$ & $12.56 \pm 0.84^{\mathrm{a}}$ & $18.78 \pm 0.90^{\mathrm{a}}$ & $59.25 \pm 2.50^{\mathrm{a}}$ \\
B & BFC-ST & $18.38 \pm 1.73^{\mathrm{b}}$ & $17.43 \pm 1.02^{\mathrm{bc}}$ & $20.28 \pm 1.03^{\mathrm{b}}$ & $43.91 \pm 3.38^{\mathrm{b}}$ \\
B & BFC-CV & $17.25 \pm 1.68^{\mathrm{bc}}$ & $16.71 \pm 0.97^{\mathrm{bc}}$ & $19.80 \pm 0.56^{\mathrm{b}}$ & $46.24 \pm 2.91^{\mathrm{bc}}$ \\
B & BFC-DM & $18.34 \pm 1.92^{\mathrm{b}}$ & $17.39 \pm 1.41^{\mathrm{bc}}$ & $20.27 \pm 1.26^{\mathrm{b}}$ & $44.00 \pm 4.39^{\mathrm{b}}$ \\
B & BFC-PPST & $15.34 \pm 1.15^{\mathrm{c}}$ & $15.73 \pm 0.98^{\mathrm{b}}$ & $19.42 \pm 0.64^{\mathrm{b}}$ & $49.51 \pm 2.69^{\mathrm{c}}$ \\
B & BFC-PP & $18.51 \pm 1.59^{\mathrm{b}}$ & $17.47 \pm 0.74^{\mathrm{c}}$ & $20.71 \pm 0.52^{\mathrm{b}}$ & $43.31 \pm 2.60^{\mathrm{b}}$ \\
C & CFC-ST & $22.61 \pm 1.57^{\mathrm{d}}$ & $18.37 \pm 1.19^{\mathrm{d}}$ & $19.93 \pm 1.11^{\mathrm{d}}$ & $39.09 \pm 3.54^{\mathrm{d}}$ \\
C & CFC-POST & $21.96 \pm 1.06^{\mathrm{d}}$ & $18.53 \pm 0.63^{\mathrm{d}}$ & $20.55 \pm 0.83^{\mathrm{d}}$ & $38.96 \pm 1.47^{\mathrm{d}}$ \\
C & CFC-PO & $21.68 \pm 1.54^{\mathrm{d}}$ & $18.77 \pm 1.19^{\mathrm{d}}$ & $20.55 \pm 0.81^{\mathrm{d}}$ & $39.00 \pm 3.43^{\mathrm{d}}$ \\
D & DFB-ST & $24.49 \pm 1.08^{\mathrm{eg}}$ & $19.67 \pm 0.75^{\mathrm{eg}}$ & $19.80 \pm 0.19^{\mathrm{ef}}$ & $36.04 \pm 1.43^{\mathrm{ef}}$ \\
D & DFB-PPST & $22.69 \pm 1.06^{\mathrm{f}}$ & $19.07 \pm 0.84^{\mathrm{fg}}$ & $20.17 \pm 0.35^{\mathrm{g}}$ & $38.08 \pm 2.13^{\mathrm{eg}}$ \\
D & DFB-POST & $25.55 \pm 1.49^{\mathrm{g}}$ & $19.71 \pm 0.53^{\mathrm{eg}}$ & $19.71 \pm 0.26^{\mathrm{e}}$ & $35.03 \pm 2.13^{\mathrm{f}}$ \\
D & DFB-PP & $22.82 \pm 0.73^{\mathrm{f}}$ & $18.67 \pm 0.38^{\mathrm{f}}$ & $19.98 \pm 0.17^{\mathrm{eg}}$ & $38.53 \pm 1.08^{\mathrm{g}}$ \\
D & DFB-PO & $23.36 \pm 0.71^{\mathrm{f}}$ & $18.99 \pm 0.44^{\mathrm{fg}}$ & $20.15 \pm 0.23^{\mathrm{f}}$ & $37.51 \pm 1.22^{\mathrm{eg}}$ \\
\hline
\end{tabular}

${ }^{\mathrm{a}-\mathrm{g}}$ For each milk (A, B, C, and D), means in columns followed by the same letter are not significantly different $(P>0.05)$ according to ANOVA.

${ }^{1}$ Mean relative percentage weight of FFA from at least one group consisting of 5 samples.

${ }^{2}$ Standard deviation of the mean.

pump used for pumping raw goat milk $\mathrm{A}$ at 13 to $15^{\circ} \mathrm{C}$ did not produce significant modifications on FFA percentage composition. Equally, pumping milk at 13 to $15^{\circ} \mathrm{C}$ both through the screw and the centrifugal pump did not promote significant modifications $(P>0.05)$ on FFA profile of goat milk B. The milk temperatures chosen during pumping are related with the values reported for maximum formation of FFA upon mechanical treatments (Wiking, 2005). Additionally, it has been reported that at temperatures lower than $31^{\circ} \mathrm{C}$, the formation of FFA is higher in the milk with large MFG both inherently and after pumping (Wiking et al., 2005). After pumping raw milk by the screw pump, as expected, no increase of FFA concentrations compared with untreated samples was found. The gentle pumping action and low working rotations of the screw pump may have contributed for this result. In contrast, modifications were expected on FFA concentrations after milk being pumped at higher rotations $(392 \times g, 2,960$ rpm) by the centrifugal pump; as already mentioned, previous studies reported that pumping raw cow milk at rotations ranging from 1,750 to $3,500 \mathrm{rpm}$ caused significant increase of FFA concentration (Escobar and Bradley, 1990). However, it has been demonstrated that the cooling of the raw milk to $4^{\circ} \mathrm{C}$ directly after milking and before pumping caused no increase in FFA (Wiking et al., 2005). Probably, the fact that the goat milk has been cooled to refrigeration temperatures $\left(+5^{\circ} \mathrm{C}\right)$ before pumping experiments could have avoided the accumulation of FFA in milk; at low temperatures the MFG seems to be more resistant to mechanical stress. The effect of temperature on MFG stability is due to the crystallization of lipids, once the temperature range of crystallization of milk fat is broad $\left(-40^{\circ} \mathrm{C}\right.$ to $\left.+40^{\circ} \mathrm{C}\right)$ and there is an evidence that a high proportion of the milk fat needs to be in the liquid phase to initiate coalescence of MFG (Wiking, 2005). Furthermore, it is important to notice that the mean diameter of MFG in goat milk is smaller than for cow milk, which eventually could have contributed to a lower friction between fat globules, reducing coalescence and the susceptibility of FFA concentrations to increase in treated milk. When MFG coalesces, small parts of MFGM probably break off together with small quantities of triglycerides and form tiny fat globules (Wiking et al., 2005) that are easily exposed to enzymatic attacks.

Significant differences were found on FFA percentage composition in the other treatments that followed the pumping experiments. The groups of samples belonging to goat milk B presented significant differences $(P<$ 0.05 ) on percentage compositions of $\mathrm{C} 4: 0, \mathrm{C} 6: 0$, and C10:0. The samples of raw goat milk that passed through the plate heat exchanger, even without heating (BFC-PPST), presented a FFA profile significantly different from the other groups of samples. This means that C10:0 acid seemed to be the most affected once its percentage weight increased from $43.91 \% \pm 3.38 \%$ (BFC-ST) to $49.51 \% \pm 2.69 \%$ (BFC-PPST) after this treatment. Consequently, this lowered the percentage weight of $\mathrm{C} 4: 0$ and $\mathrm{C} 6: 0$, whose increase was not noticed in these treated samples. The presumably high shear rates imposed on milk during its passage through the thin channels of the PHE may have damaged the MFG, and this fact could be an explanation for the increase 
$A \square B \square C \square D$

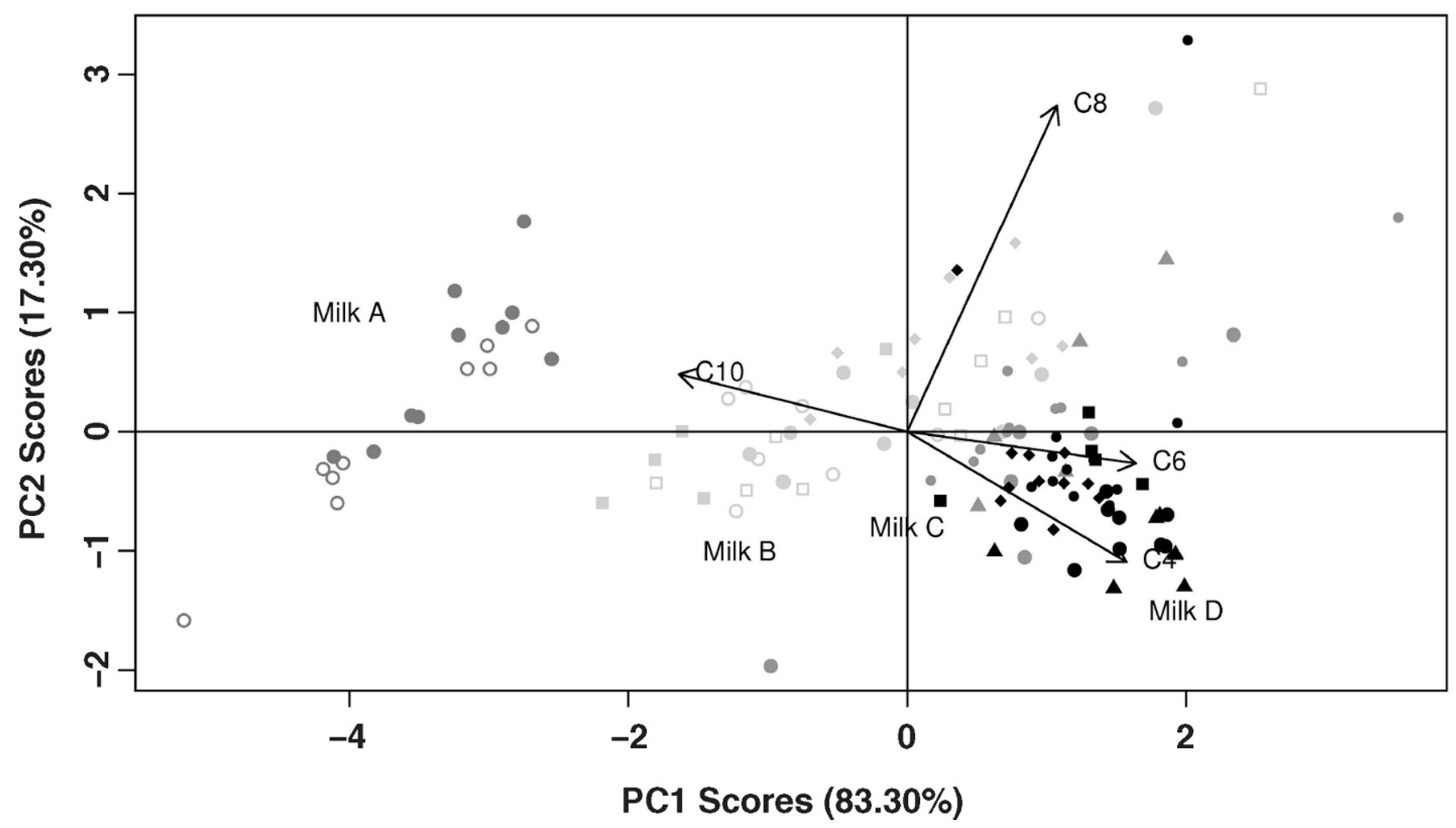

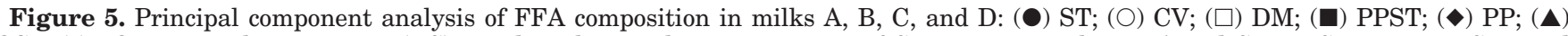
POST; (•) PO. Principal components (PC) 1 and 2 relate to the concentration of C10:0 against other FFA and C4:0 + C6:0 against C8:0 and C10:0, respectively.

of the percentage weight of C10:0 acid in BFC-PPST samples. However, the FFA profile, and in particular the percentage weight of $\mathrm{C} 10: 0$ of the samples that passed through the PHE combined with pasteurization at $75^{\circ} \mathrm{C}$ for $15 \mathrm{~s}$ (BFC-PP), was not affected. Due to their relatively high volatility, the lower fatty acids (C4:0 to C10:0), can have been lost during the procedure. In this case, partial volatilization of C10:0 during pasteurization may have masked the effect previously observed in milk samples that passed through PHE without heating. However, it will be possible to provide evidence in the following section that these observations were not reproducible and also not confirmed by multivariate methods of data analysis.

Concerning goat milk $\mathrm{C}$, no significant differences $(P>0.05)$ were noticed between raw and ohmically pasteurized goat milk samples. It is important to notice that samples of this milk (raw and pasteurized) were not subjected to the passage through the PHE. Probably the mechanical stress imposed by the $\mathrm{OH}$ was lower than that of PHE observed in goat milk B. Additionally, the percentage weights of FFA were not reduced, thus indicating that the volatilization of FFA presumably did not occur during pasteurization. Contrary to milk B and $\mathrm{C}$, in goat milk $\mathrm{D}$, where 2 pasteurization processes (ohmic and conventional) were compared and a second PHE was used as cooling unit (such as in milk B), it was possible to observe that the different groups of treated samples showed significant differences $(P<$ 0.05) on percentage composition of $\mathrm{C} 4: 0, \mathrm{C} 6: 0, \mathrm{C} 8: 0$, and $\mathrm{C} 10: 0$. The percentage weight of $\mathrm{C} 10: 0$ was higher in samples that passed through the PHE (DFB-PPST) than those which passed in the OH (DFB-POST), even without being heated, confirming the tendency already observed in milk B of the increase of C10:0 after the passage through PHE. However in milk D, both pasteurization processes influenced the FFA profile. In fact, samples pasteurized either by ohmic (DFB-PO) or conventional (DFB-PP) pasteurization have presented higher contents of $\mathrm{C} 10: 0$ than samples of raw goat milk collected after passing through OH (DFB-POST). Additionally, the samples pasteurized in the PHE (DFBPP) have also shown higher contents of C10:0 than the untreated raw samples (DFB-ST); this occurrence was not observed for samples pasteurized in the $\mathrm{OH}$ (see Table 5). In this milk, C8:0 also presented the same 


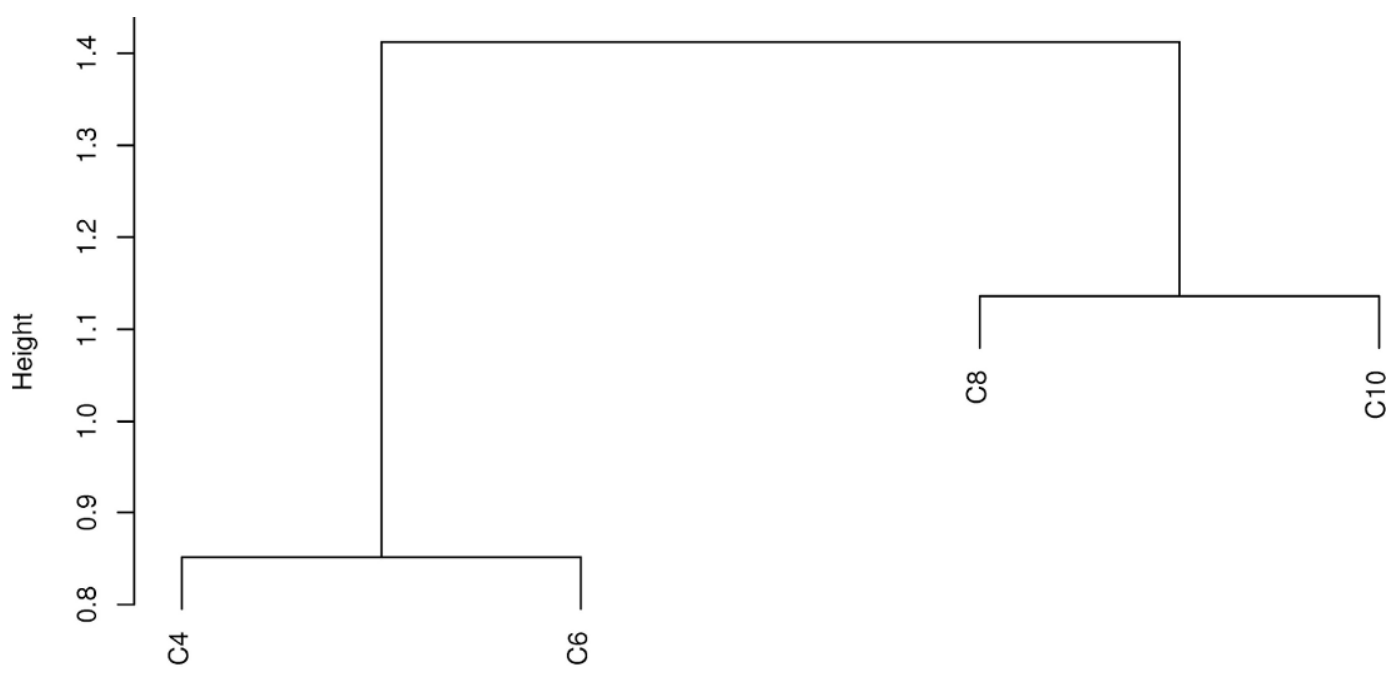

Figure 6. Hierarchical clustering between principal component analysis (PCA) loadings.

pattern of variation reported for $\mathrm{C} 10: 0$, with the exception that no significant differences $(P>0.05)$ were found between DFB-PP and DFB-ST samples. Generally, concentrations of $\mathrm{C} 4: 0$ and $\mathrm{C} 6: 0$ were kept constant for the several treatments to which milk D was subjected; thus, the differences found on percentage weights of those FFA seemed to be mainly a result from the variations in $\mathrm{C} 8: 0$ and $\mathrm{C} 10: 0$ contents.

In short, through the univariate analysis it was possible to observe significant modifications on FFA profile after some of the treatments applied, particularly after the passage through the heating units and pasteurization; however, these effects were not visible for all the samples of milk analyzed. Furthermore, as mentioned before, several physical, chemical, and biological vari- ables may influence FFA composition, which explains the differences found in FFA composition between the 4 untreated goat milk samples (A, B, C, and D). This led to the decision of applying multivariate methods of data analysis to compare together all the samples from all the different milks, and consequently, to get more reliable conclusions about the effects of different treatments in FFA. Therefore, the differences between the treatments on FFA profile were emphasized during PCA and hierarchical cluster analysis.

\section{Multivariate Analysis}

According with PCA (see Figure 5), 2 main PC accounted for $99.60 \%$ of the total variability: PC1 (82.30\%)

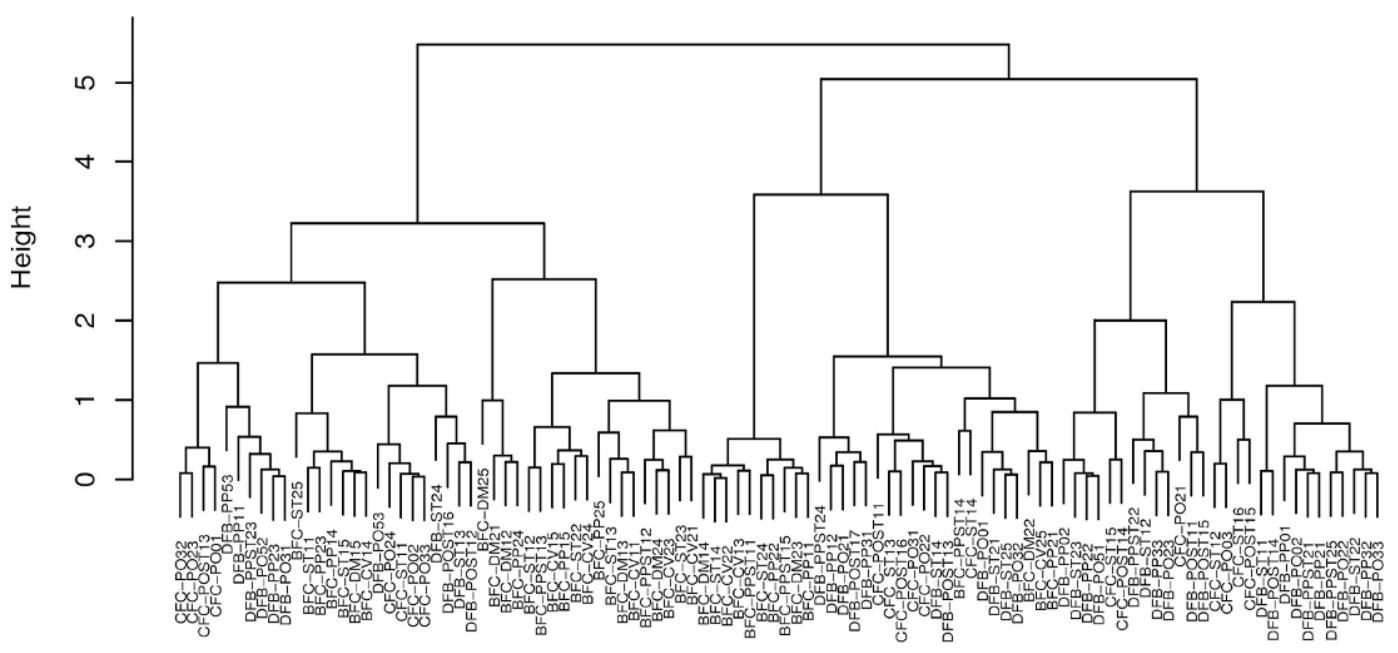

Figure 7. Hierarchical clustering between principal component analysis (PCA) scores. 
and PC2 (17.30\%). The PC1 is primarily responsible for the difference between the contents of C10:0 and contents of the other FFA (C4:0, C6:0, and C8:0). The PC2 relates the contents of both $\mathrm{C} 4: 0$ and $\mathrm{C} 6: 0$ against $\mathrm{C} 8: 0$ and C10:0. Like in univariate analysis, a discriminant multivariate algorithm showed consistency on the differentiation of milk samples: through PCA it was possible to conclude that $\mathrm{C} 10: 0$ discriminates the different milks and treated samples in an opposite way to C4:0 and C6:0. Therefore, the percentage weight of C10:0 could be used to distinguish samples of goat milk with different FFA profile. Additionally, hierarchical cluster analysis applied to all quantitative data obtained (see Figure 6) clearly showed 2 clusters: one constituted by short-chain FFA (C4:0 and C6:0), and the other by medium-chain FFA (C8:0 and C10:0). These correlations found between FFA are in agreement with those found for fatty acids in goat milk (Chilliard and Ferlay, 2004) and can result mainly from the different metabolic pathways and nutrient fluxes involved in milk fat synthesis; when the bioavailability of longchain fatty acids (oleic, stearic, and linolenic) increases (as a result of either increased dietary intake or body lipid mobilization), caprylic to palmitic fatty acids secretion decreases, and their concentration decreases even more through dilution in a larger quantity of long-chain fatty acids. Contrary to medium-chain fatty acids, short-chain fatty acids concentrations (C4:0 and C6:0) are classically either unchanged or only slightly reduced by increased lipid supplementation in the diet or body lipid mobilization (Chilliard and Ferlay, 2004). That specificity is probably due to the fact that those fatty acids are partly synthesized by metabolic pathways not dependent on acetyl-CoA carboxylase (Bauman and Davis, 1974; Palmquist and Jenkins, 1980). Therefore, the successive decrease of the percentage content of C10:0 observed in samples of raw untreated goat milk could have been a result from variations on goat milk fat composition once goat milk was collected toward the end of lactation stage. Generally, fat content is high in the initial days of lactation and gradually decreases thereafter (Gomes et al., 2004). Based upon these facts and attending to the fact that percentage weight of C10:0 accounted in great extent to the variability observed through PCA, evaluation of this free fatty acid eventually could be used to discriminate goat milk samples with different fat composition. This also means that milk with a lower fat content and with less concentration of long- and medium-chain fatty acids can also be susceptible to the development of shortchain FFA. However, further research is needed to confirm the relationship between fat and C10:0 contents; differences observed could also have been promoted by other factors not controlled in this experimental work, such as diet, incomplete lipid biosynthesis, or spontaneous lipolysis occurring during refrigerated storage of bulk milk.

Finally, throughout cluster analysis it was also possible to sort the different treated goat milk samples into groups based on the similarity of FFA percentage composition. According to this analysis, 3 groups of different size can be established at height over 4 , and several samples appear to be associated, as the dendrogram in Figure 7 illustrates. However, inside each cluster different treated samples were not found; it was not possible to establish a pattern among the several treatments. In agreement with univariate analysis, multivariate analysis showed that the variability on FFA percentage weight determined through combination of SPME and GC techniques, apparently, was not a result of the physical treatments imposed by pumping. Contrary to some evidence taken from univariate analysis (namely, the reported differences between some of the treatments), multivariate tools also indicate that the combination of physical (passage of milk through heating units, without heating) and thermal treatments introduced by ohmic and conventional pasteurization do not explain the meaning of the associations observed in the results. The fact that processed samples (pasteurized at $75^{\circ} \mathrm{C}$ for $15 \mathrm{~s}$ both by $\mathrm{PHE}$ and $\mathrm{OH}$ ) did not differentiate clearly from raw treated and untreated samples suggests that damage on MFGM, lipolytic action and consequently excessive liberation of FFA were not promoted by the treatments applied. Therefore, the electric fields applied during ohmic heating did not introduce relevant modifications on FFA profile of goat milk. Through multivariate analysis it was possible to conclude that the variability of the FFA percentage composition observed in untreated raw goat milk samples was much greater than the variability introduced by the studied treatments. The meanings of the associations observed between samples in hierarchical cluster analysis are then open for further research.

\section{CONCLUSIONS}

This exploratory study led to the following conclusions:

I. Combination of SPME and gas chromatography techniques applied for the determination of short- and medium-chain of FFA from goat milk resulted in a method with good reproducibility, in particular for butyric, caproic, caprylic, and capric FFA.

II. The most abundant FFA in the undamaged raw goat milk samples analyzed were those of medium carbon chain, such as caprylic and capric. In fact, capric acid seems to be the most affected 
by the oscillations of goat milk composition promoted both by environmental and biochemical factors, and for this reason its evaluation can be useful to distinguish goat's milk with different FFA composition.

III. Multivariate analysis applied to all quantitative data provided evidence that gentle pumping conditions and HTST pasteurization did not promote significant modifications on the contents of short- and medium-chain FFA. Further, ohmic heating did not bring modifications to FFA content, indicating that this technology can be introduced in goat milk pasteurization without affecting negatively the quality of goat milk flavor.

\section{REFERENCES}

Anderson, M. 1983. Milk lipases and off-flavour development. J. Soc. Dairy Technol. 36:3-7.

Bauman, D., and C. Davis. 1974. Biosynthesis of milk fat. Pages 3175 in Lactation: A Comprehensive Treatise. B. Larson and V. Smith, ed. Academic Press Inc., New York, NY.

Chilliard, Y., and A. Ferlay. 2004. Dietary lipids and forages interactions on cow and goat milk fatty acid composition and sensory properties. Reprod. Nutr. Dev. 44:467-492.

Deeth, H. 2006. Lipoprotein lipase and lipolysis in milk: A review. Int. Dairy J. 16:555-562.

Escobar, G. J., and R. Bradley. 1990. Effect of mechanical treatment on the free fatty acids content of raw milk. J. Dairy Sci. 73:2050-2060.
Fox, P., and P. McSweeney. 1998. Dairy Chemistry and Biochemistry. 1st ed. Blackie Academic \& Professional, London, UK.

Gomes, V., A. M. Libera, K. M. Madureira, and W. P. Arajo. 2004. Influence of lactation stage on goat (Capra hircus) milk composition. Braz. J. Vet. Res. Anim. Sci. 4:339-342.

González-Córdova, A., and B. Vallejo-Cordoba. 2001. Quantitative determination of short chain free fatty acids in milk using solidphase micro-extraction and gas chromatography. J. Agric. Food Chem. 49:4603-4608.

González-Córdova, A., and B. Vallejo-Cordoba. 2003. Detection and prediction of hydrolytic rancidity in milk by multiple regression analysis of short-chain free fatty acids determined by solid phase microextraction gas chromatography and quantitative flavor intensity assessment. J. Agric. Food Chem. 51:7127-7131.

Krzanowski, W. 1998. Principles of multivariate analysis. Oxford University Press, Oxford, UK.

Palmquist, D., and T. Jenkins. 1980. Fat in lactation rations for dairy: A review. J. Dairy Sci. 63:1-14.

Park, Y. 2001. Proteolysis and lipolysis of goat milk cheese. J. Dairy Sci. 84:E84-E92.

Parrott, D. 1992. Use of ohmic heating for aseptic processing of food particulates. Food Technol. 46:68-72.

Raynal-Ljutovac, K., Y. Park, F. Gaucheron, and S. Bouhallab. 2006. Heat stability and enzymatic modifications of goat and sheep milk. Small Rumin. Res. 68:207-220.

Wiking, L. 2005. Lipolysis with special reference to automatic milking systems. PhD Thesis. Swedish University of Agricultural Sciences, Uppsala.

Wiking, L., H. Bertram, L. Björck, and J. Nielsen. 2005. Evaluation of cooling strategies for pumping of milk-Impact of fatty acid composition on free fatty acid levels. J. Dairy Res. 72:476-481.

Zulueta, A., M. Esteve, I. Frasquet, and A. Frgola. 2007. Fatty acid profile changes during orange juice-milk beverage processing by high-pulsed electric field. Eur. J. Lipid Sci. Technol. 109:25-31. 